\title{
Less acid + less bleeding $=$ better outcomes and more money!
}

\author{
Robert Enns MD
}

\begin{abstract}
ARTICLE
Barkun AN, Herba K, Adam V, Kennedy W, Fallone CA, Bardou M. High-dose intravenous proton pump inhibition following endoscopic therapy in the acute management of patients with bleeding peptic ulcers in the USA and Canada: A cost-effectiveness analysis. Aliment Pharmacol Ther 2004;19:591-600.
\end{abstract}

\begin{abstract}
ARTICLE SUMMARY
The use of acid suppression in the setting of gastrointestinal bleeding is based on laboratory studies, some of which were conducted over 25 years ago (1). These studies suggested that an acid milieu adversely affects bleeding through several mechanisms:
\end{abstract}

- pepsin remains activated, resulting in clot digestion. This process can be inhibited by creating an alkaline environment, or simply by removing pepsin $(2,3)$;

- impaired platelet aggregation; and

- accelerated fibrinolysis.

Notwithstanding these experimental findings, early studies found that histamine-2 receptor antagonists provided marginal (if any) benefit for bleeding. Most recently, the development of oral (and subsequently intravenous [IV]) proton pump inhibitors (PPIs) has resulted in renewed interest in acid suppression for upper gastrointestinal (UGI) hemorrhage.

The pivotal trial that resulted in many changes in the use of acid suppression was published by Lau et al (4) in 2000. In this trial, patients with high-risk ulcer lesions (as determined by endoscopy) were endoscopically treated in the standard fashion and randomized to either IV omeprazole ( $80 \mathrm{mg}$ bolus followed by continuous infusion of $8 \mathrm{mg} / \mathrm{h}$ ) or placebo for a period of $72 \mathrm{~h}$. The results were impressive: only $6.7 \%$ of patients receiving IV PPIs experienced rebleeding, compared with $22.5 \%$ in the placebo group. There were also nonsignificant trends toward decreased mortality and the need for surgery.

These results were readily accepted in many countries, leading to the inclusion of IV PPIs in hospital formularies. In 2002, we evaluated the first 854 patients given an IV PPI in six Vancouver-area hospitals and found that it was administered for suspected or proven UGI hemorrhage $90 \%$ of the time. Almost $60 \%$ of patients received the medication before endoscopy, a situation that had not been studied clinically.

In the paper under review, Barkun et al presented a costeffectiveness analysis of high-dose IV PPI following endoscopic therapy. This is clearly different from a cost-effectiveness analysis of IV PPI before endoscopy in all patients with UGI bleeding, which we published in 2003 (5). Dr Barkun's group assessed patients in both Canadian and American settings. The model is updated with the latest studies, including recent Canadian 'real-life' data from the Registry of Upper Gastrointestinal Bleeding and Endoscopy (RUGBE) (6). 'High-risk' lesions were appropriately defined as lesions with active bleeding, visible vessels or adherent clots. Patients in the high-dose IV PPI branch of the decision tree received an $80 \mathrm{mg}$ bolus followed by $8 \mathrm{mg} / \mathrm{h}$ of IV pantoprazole within $12 \mathrm{~h}$ of endoscopy. The 'no IV PPI' group received a $40 \mathrm{mg}$ IV bolus for the first day, followed by oral pantoprazole $40 \mathrm{mg}$ daily for the remainder of their hospitalization. Rebleeding rates were derived from studies by Lau et al (4) and Lin et al (7) $(5.8 \%$ for IV PPI versus $22.9 \%$ for placebo).

Costs were evaluated from the perspective of a third-party payer in both American and Canadian settings. American estimates of length of stay were obtained from the Nationwide Inpatient Sample 2000 and the Canadian ones from a combination of the Canadian Institute for Health Information and RUGBE. Sensitivity and threshold analyses were subsequently used to assess the robustness of the results.

In short, the use of high-dose IV PPIs following endoscopic therapy for three days was both more effective and less costly than not providing it. This analysis was robust in a variety of clinical scenarios and withstood a series of threshold analyses for both American and Canadian settings. 
In theory, there are four possible outcomes when the cost and effectiveness of a new treatment are evaluated: added cost with poorer outcome, added cost with improved outcome, decreased cost with poorer outcome or decreased cost with improved outcome. It is relatively uncommon for a new intervention (such as high-dose IV PPI) to result in cost savings as well as improved outcomes.

Several limitations of a hypothetical cost analysis must be considered when trying to apply the results clinically. The use of IV PPIs has grown throughout Canada, and some of this use has been inappropriate. We are presently reassessing the use of IV PPIs in our own institution and, even in the preliminary analysis, it is apparent that the prescribing of this medication has been expanded to situations not considered in this cost analysis. For example, over $40 \%$ of patients at our institution receive bolus infusions before endoscopic examination. Additionally, many patients without UGI bleeding are now being given this medication, including patients who are receiving prophylaxis for gastrointestinal bleeding in an intensive care unit setting and patients who are given 'nothing by mouth'. Inappropriate use of this drug might increase resource utilization without significant clinical benefit.

The other area of debate is the role of oral PPIs. In principle, they should be a less expensive alternative that does not sacrifice clinical benefits. Several studies have demonstrated the benefit of oral PPIs for acute UGI bleeding $(8,9)$; however, I am not optimistic that a 'head-to-head' comparison with IV PPIs will be undertaken in the near future. Because both oral and IV formulations have been demonstrated to have positive clinical effects, the differences between the two are likely to be relatively small, and a large sample size would be required to demonstrate a significant difference.

For now, we can be comfortable that acid suppression improves outcomes in high-risk UGI bleeding. The best data involve IV PPI given at a high dose $(80 \mathrm{mg}$ bolus with $8 \mathrm{mg} / \mathrm{h}$ continuous infusion for $72 \mathrm{~h}$ ) used in conjunction with endoscopic therapy. Continued education is required to ensure appropriate use of these medications, so that maximal clinical benefit is derived from use of our limited health care resources.

\section{Robert Enns MD \\ St Paul's Hospital \\ University of British Columbia \\ Vancouver, British Columbia}

\section{REFERENCES}

1. Green FW Jr, Kaplan MM, Curtis LE, Levine PH. Effect of acid and pepsin on blood coagulation and platelet aggregation. A possible contributor prolonged gastroduodenal mucosal hemorrhage. Gastroenterology 1978;74:38-43.

2. Berstad A. Does profound acid inhibition improve haemostasis in peptic ulcer bleeding? Scand J Gastroenterol 1997;32:396-8.

3. Patchett SE, Enright H, Afdhal N, O'Connell W, O'Donoghue DP. Clot lysis by gastric juice: An in vitro study. Gut 1989;30:1704-7.

4. Lau JY, Sung JJ, Lee KK, et al. Effect of intravenous omeprazole on recurrent bleeding after endoscopic treatment of bleeding peptic ulcers. N Engl J Med 2000;343:310-6.
5. Enns RA, Gagnon YM, Rioux KP, Levy AR. Cost-effectiveness in Canada of intravenous proton pump inhibitors for all patients presenting with acute upper gastrointestinal bleeding. Aliment Pharmacol Ther 2003;17:225-33.

6. Barkun A, Sabbah S, Enns R, et al. RUGBE Investigators. The Canadian Registry on Nonvariceal Upper Gastrointestinal Bleeding and Endoscopy (RUGBE): Endoscopic hemostasis and proton pump inhibition are associated with improved outcomes in a real-life setting. Am J Gastroenterol 2004;99:1238-46.

7. Lin HJ, Lo WC, Lee FY, Perng CL, Tseng GY. A prospective randomized comparative trial showing that omeprazole prevents rebleeding in patients with bleeding peptic ulcer after successful endoscopic therapy. Arch Intern Med 1998;158:54-8.

8. Javid G, Masoodi I, Zargar SA, et al. Omeprazole as adjuvant therapy to endoscopic combination injection sclerotherapy for treating bleeding peptic ulcer. Am J Med 2001;111:280-4.

9. Khuroo MS, Yattoo GN, Javid G, et al. A comparison of omeprazole and placebo for bleeding peptic ulcer. N Engl J Med $1997 ; 336: 1054-8$

The authors respond:

Dr Enns' commentary is an excellent up-to-date overview of the current situation of acid suppression for patients with nonvariceal upper gastrointestinal bleeding. The only additional remarks I would make are the conclusions of recent decision modelling that our group has just published (1). It concludes that, based on the extrapolation of current data, intravenous high-dose proton pump inhibitor (PPI) administration appears to be more cost-effective than its oral high-dose alternative. This comparison required the incorporation of nonhead-tohead clinical trials, however, and should be seen as an exploratory analysis. A more accurate determination of the effectiveness (and, thus, the cost-effectiveness) of the preendoscopic administration of PPI awaits the results of ongoing clinical trials. None of the published decision models to date has taken into account the actual overall utilization pattern of intravenous and oral PPIs in a hospital setting; this is a pertinent, yet different, clinical question. Dr Enns nonetheless is correct in questioning such overall costs. It is our hope that the available evidence, as summarized in recently published international guidelines on nonvariceal upper gastrointestinal bleeding (2), would contribute to optimizing the utilization of PPIs for this indication.

Alan Barkun MD CM MSc Division of Gastroenterology Montreal General Hospital Site Montreal, Quebec

\section{REFERENCES}

1. Barkun AN, Herba K, Adam V, Kennedy W, Fallone CA, Bardou M. The cost-effectiveness of high-dose oral proton pump inhibition after endoscopy in the acute treatment of peptic ulcer bleeding. Aliment Pharmacol Ther 2004;20:195-202.

2. Barkun A, Bardou M, Marshall JK. The Nonvariceal Upper GI Bleeding Consensus Conference Group. Consensus recommendations for managing patients with nonvariceal upper gastrointestinal bleeding. Ann Intern Med 2003;139:843-57. 


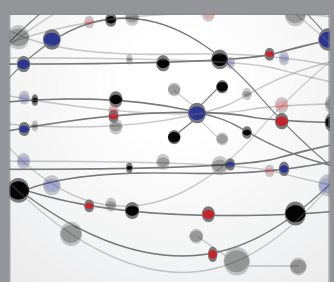

The Scientific World Journal
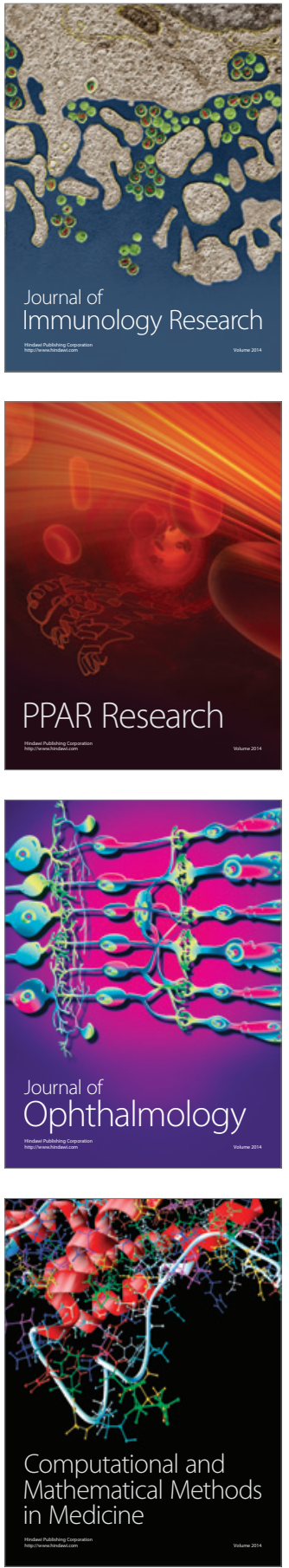

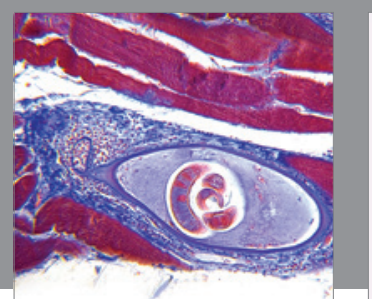

Gastroenterology Research and Practice

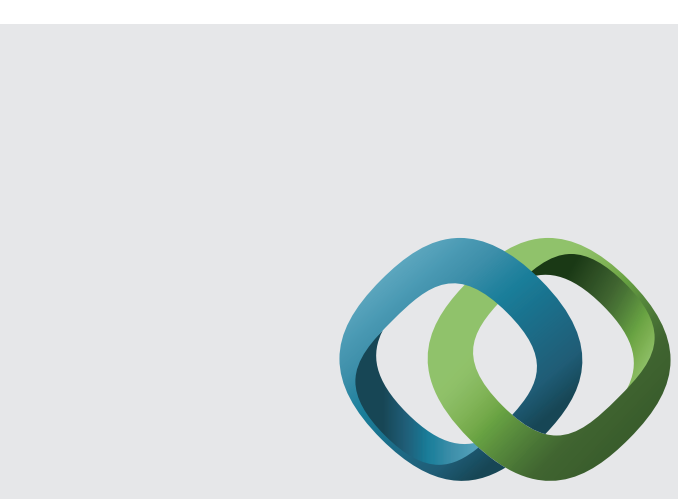

\section{Hindawi}

Submit your manuscripts at

http://www.hindawi.com
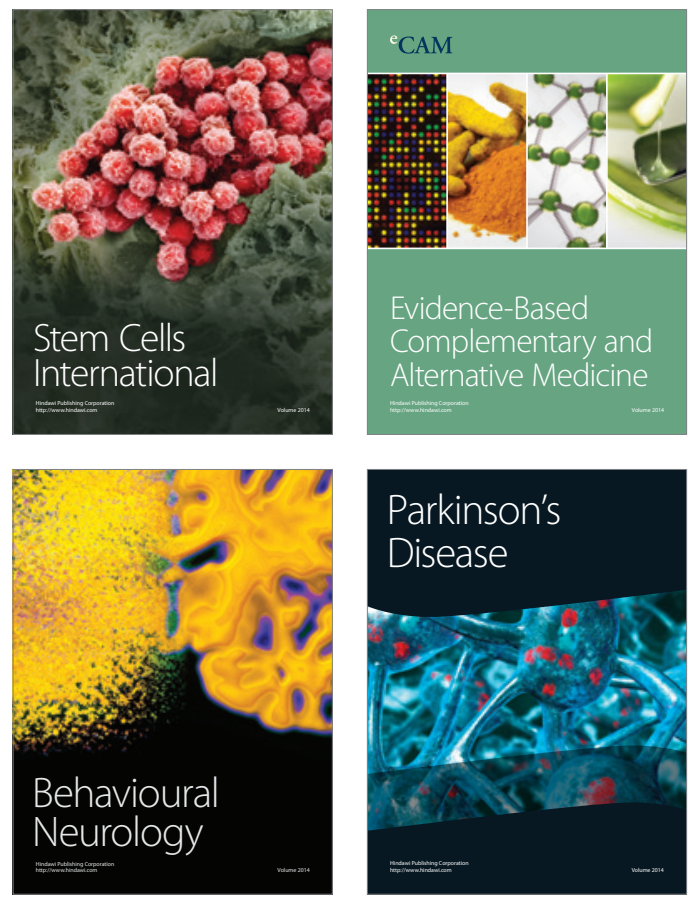
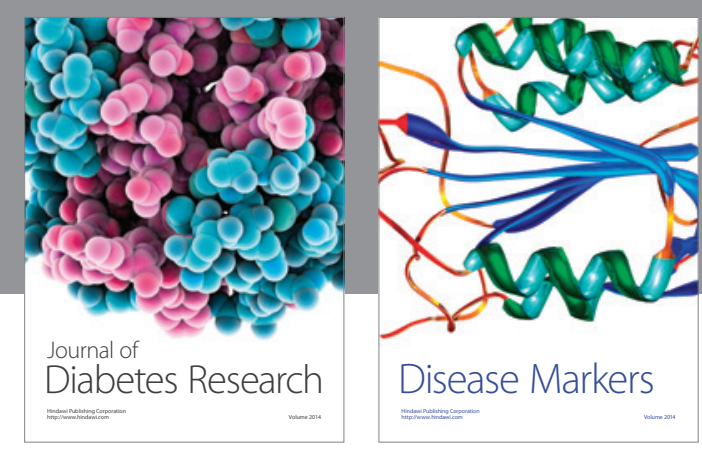

Disease Markers
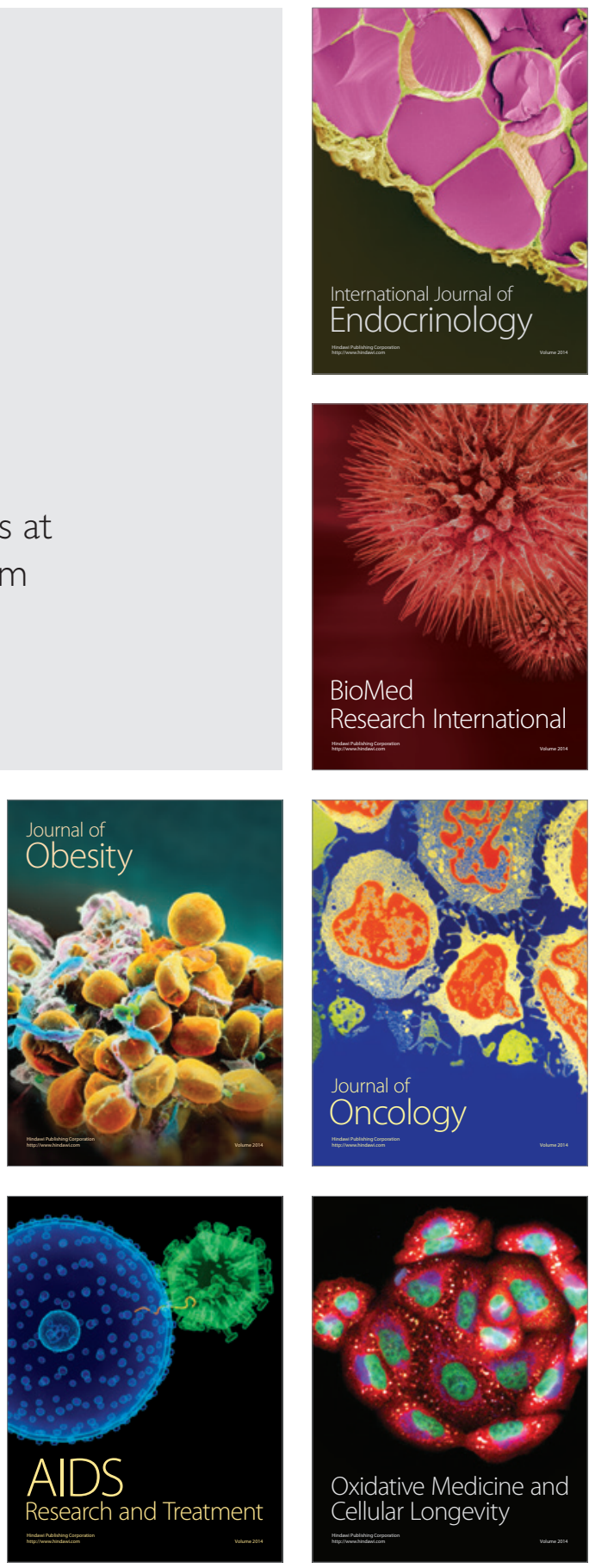